\title{
Correction for a measurement artifact of the Multi-Angle Absorption Photometer (MAAP) at high black carbon mass concentration levels
}

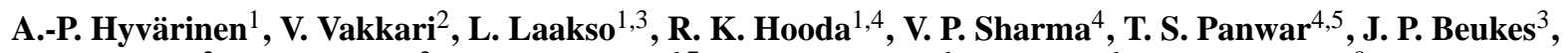

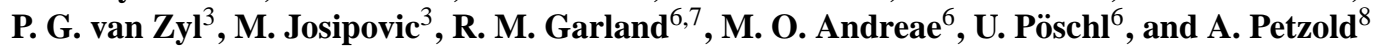 \\ ${ }^{1}$ Finnish Meteorological Institute, P.O. Box 503, 00101 Helsinki, Finland \\ ${ }^{2}$ Department of Physics, University of Helsinki, P.O. BOX 64, 00014 Helsinki, Finland \\ ${ }^{3}$ School of Physical and Chemical Sciences, North-West University, Potchefstroom, South Africa \\ ${ }^{4}$ The Energy and Resources Institute (TERI), Darbari Seth Block, IHC Complex, Lodhi Road, 110003 New Delhi, India \\ ${ }^{5}$ WWF India, Lodhi Road, 110003 New Delhi, India \\ ${ }^{6}$ Max Planck Institute for Chemistry, P.O. Box 3060, 55020 Mainz, Germany \\ ${ }^{7}$ Natural Resources and the Environment, The Council for Scientific and Industrial Research (CSIR), Pretoria, South Africa \\ ${ }^{8}$ Forschungszentrum Jülich GmbH, Institute of Energy and Climate Research IEK-8: Troposphere, 52425 Jülich, Germany
}

Correspondence to: A.-P. Hyvärinen (antti.hyvarinen@fmi.fi)

Received: 10 August 2012 - Published in Atmos. Meas. Tech. Discuss.: 12 September 2012

Revised: 13 December 2012 - Accepted: 14 December 2012 - Published: 11 January 2013

\begin{abstract}
The Multi-Angle Absorption Photometer (MAAP) is a widely-used instrument for aerosol black carbon (BC) measurements. In this paper, we show correction methods for an artifact found to affect the instrument accuracy in environments characterized by high black carbon concentrations. The artifact occurs after a filter spot change - as BC mass is accumulated on a fresh filter spot, the attenuation of the light (raw signal) is weaker than anticipated. This causes a sudden decrease, followed by a gradual increase in measured $\mathrm{BC}$ concentration. The artifact is present in the data when the BC concentration exceeds $\sim 3 \mu \mathrm{g} \mathrm{m}^{-3}$ at the typical MAAP flow rate of $16.7 \mathrm{~L} \mathrm{~min}^{-1}$ or $1 \mathrm{~m}^{3} \mathrm{~h}^{-1}$. The artifact is caused by erroneous dark counts in the photodetector measuring the transmitted light, in combination with an instrument internal averaging procedure of the photodetector raw signals. It was found that, in addition to the erroneous temporal response of the data, concentrations higher than $9 \mu \mathrm{g} \mathrm{m}^{-3}$ (at the flow rate of $16.7 \mathrm{~L} \mathrm{~min}^{-1}$ ) are underestimated by the MAAP. The underestimation increases with increasing $\mathrm{BC}$ accumulation rate. At a flow rate of $16.7 \mathrm{~L} \mathrm{~min}^{-1}$ and concentration of about $24 \mu \mathrm{g} \mathrm{m}{ }^{-3}$ (BC accumulation rate $\sim 0.4 \mu \mathrm{g} \mathrm{min}^{-1}$ ), the underestimation is about $30 \%$. There are two ways of overcoming the MAAP artifact. One method is by logging the raw
\end{abstract}

signal of the $165^{\circ}$ photomultiplier measuring the reflected light from the filter spot. As this signal is not affected by the artifact, it can be converted to approximately correct absorption and $\mathrm{BC}$ values. However, as the typical print formats of the MAAP do not give the reflected signal as an output, a semi-empirical correction method was developed based on laboratory experiments to correct for the results in the post-processing phase. The correction function was applied to three MAAP datasets from Gual Pahari (India), Beijing (China), and Welgegund (South Africa). In Beijing, the results could also be compared against a photoacoustic spectrometer (PAS). The correction improved the quality of all three MAAP datasets substantially, even though the individual instruments operated at different flow rates and in different environments.

\section{Introduction}

A widely used method for measuring atmospheric black carbon (BC) mass concentration involves the determination of absorption of an aerosol sample collected on an appropriate filter matrix. The most common instruments utilized 
today for this purpose are the filter-tape-based Aethalometer (Hansen et al., 1984), Multi-Angle Absorption Photometer (MAAP) (Petzold et al., 2002; Petzold and Schönlinner, 2004), and the single-filter-based Particle Soot Absorption Photometer (PSAP) (e.g., Bond et al., 1999). Since BC by definition cannot be unambiguously measured with these instruments, it is customary to refer to the measured carbonaceous light absorbing aerosol constituent as equivalent $\mathrm{BC}$ (BCe) or light-absorbing carbon (LAC). For the sake of simplicity, we use the term $\mathrm{BC}$ throughout. For a detailed discussion of the nomenclature used for black carbon or light-absorbing carbon components of the atmospheric aerosol, see, e.g., Bond and Bergstrom (2006) and Andreae and Gelencsér (2006).

It is well known that filter-based BC measurements suffer from several artifacts. These include the filter loading effect that causes a decrease in the measured $\mathrm{BC}$ concentration with increasing filter load, and the sample matrix effect that causes scattering aerosols on the filter to increase the measured BC concentration. These artifacts can be corrected to some extent by using different numerical methods (e.g., ond et al., 1999; Weingartner et al., 2003; Arnott et al., 2005; Virkkula et al., 2007; Collaud Coen et al., 2010). All of the correction schemes have their advantages and disadvantages under field conditions. Thus far, the MAAP has been deemed as the most reliable filter-based instrument for measurement of $\mathrm{BC}$, since the instrument design and software take the typical filter-related artifact effects into account.

We have conducted aerosol field measurements in Gual Pahari (India) from December 2007 to January 2010, including BC measurements with the MAAP (Hyvärinen et al., 2010). During this campaign, we observed that at high BC concentrations the MAAP is not free of measurement artifacts. The observed artifact is different from those seen with other filter-based BC instruments, and to our knowledge has not been reported before in the literature. Here, we quantify this artifact with the assistance of laboratory measurements utilizing two MAAPs operating at different flow rates. The focus of this paper is to raise awareness of the MAAP artifact within the aerosol community, and to demonstrate how the artifact can be circumvented by logging the reflected photodetector signal. In addition, we present a method for correcting the results from the typical instrument print formats in the post-processing phase. The correction is applied to three MAAP datasets: Gual Pahari (India) (Hyvärinen et al., 2010); Beijing (Garland et al., 2009) (China), and Welgegund (South Africa) (Beukes et al., 2012; www.welgegund.org). In Beijing, the results could be compared against a photoacoustic spectrometer (PAS; Garland et al., 2009).

\section{Multi-Angle Absorption Photometer}

The Thermo Scientific Model 5012 MAAP measures the aerosol $\mathrm{BC}$ mass concentration at a single nominal

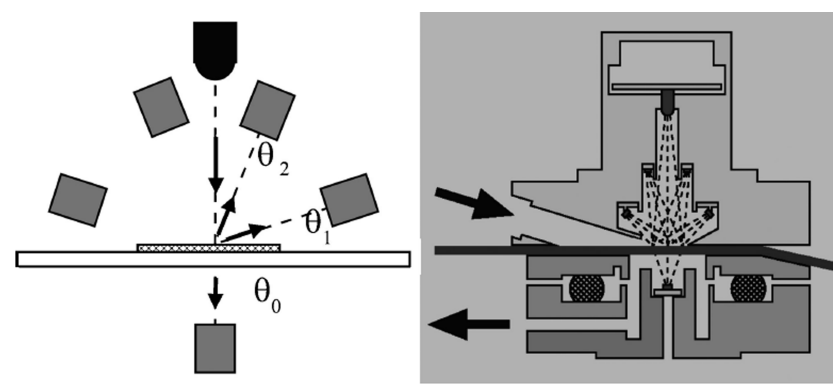

Fig. 1. Schematic of the MAAP. The transmitted light is measured with the photodetector at $\theta_{0}=0^{\circ}$, and the reflected light with the photodetectors at $\theta_{1}=130^{\circ}$ and $\theta_{2}=165^{\circ}$. (Figure from: "Aerosol Science and Technology: Evaluation of Multiangle Absorption Photometry for Measuring Aerosol Light Absorption", 39, 40-51, Copyright 2005, Mount Laurel, NJ, reprinted with permission.)

wavelength $670 \mathrm{~nm}$. However the true wavelength has later been measured to be $637 \mathrm{~nm}$ (Müller et al., 2011). The typical filter-loading-related artifacts are already taken into account in the design and the internal programming of the instrument. In inter-comparison tests, the MAAP has been found to give reliable results of light absorption by aerosols (e.g., Sheridan et al., 2005; Petzold et al., 2005).

The principle of measuring the absorption coefficient $\left(b_{\mathrm{AP}}\right)$ using multi-angle absorption photometry has been well documented during instrument development (Petzold and Schönlinner, 2004). The key principle is that, in addition to the typical transmission measurement, the signals scattered to angles at 130 and $165^{\circ}$ are also measured (Fig. 1). Additionally, radiative processes are modeled by a radiative transfer scheme for the particle-loaded filter, the aerosolfilter layer alone, and the blank filter alone (Hänel, 1987). The final output of the radiative model is the single scattering albedo $\left(\omega_{\text {FILTER }}\right)$ and the optical depth $\left(\tau_{\text {FILTER }}\right)$ of the aerosol loaded filter layer that match the measured transmitted and reflected signals. From these values, the absorption coefficient of the MAAP ( $\left.b_{\text {AP,MAAP }}\right)$ is given by the following equation (Petzold et al., 2005):

$b_{\mathrm{AP}, \mathrm{MAAP}} \approx b_{\mathrm{ATN}, \mathrm{MAAP}}=-\frac{A}{V}\left(1-\omega_{\mathrm{FILTER}}\right) \times \tau_{\text {FILTER }}$

where $b_{\text {ATN,MAAP }}$ is a method-dependent coefficient related to absorption, $A$ is the filter spot area, and $V$ is the sampled volume.

Since the values of $\omega_{\text {FILTER }}$ and $\tau_{\text {FILTER }}$ at a given time $t$ always refer to the initial values of the particle-free filter, the incremental increase in $b_{\mathrm{AP}, \mathrm{MAAP}}$ during time interval $t_{i}-t_{i-1}$ is determined from

$$
\begin{aligned}
b_{\text {AP,MAAP }}\left(t_{i}\right) & =-\frac{A}{V} \times\left[\left(1-\omega_{\text {FILTER }}\left(t_{i}\right)\right) \times \tau_{\text {FILTER }}\left(t_{i}\right)\right. \\
& \left.-\left(1-\omega_{\text {FILTER }}\left(t_{i-1}\right)\right) \times \tau_{\text {FILTER }}\left(t_{i-1}\right)\right] .
\end{aligned}
$$

The air flow is drawn through a glass fiber filter tape, and the ambient aerosol is collected on a sampling spot of $A=2 \mathrm{~cm}^{2}$ 
area. The sample volume flow through the instrument is measured continuously by the pressure drop across an orifice. For default instrument settings, the filter tape is moved forward to the next blank sampling spot after the transmission of the particle-loaded spot has decreased below $20 \%$. The initial signals at detection angles 0,130 and $165^{\circ}$ for the particlefree sample spot are determined after the filter spot change during a zeroing procedure, while respective values for the particle-loaded filter are measured at distinct time intervals during aerosol sampling.

In the commercial software version provided by Thermo Instruments, the attenuation of light by the deposited aerosol is measured in time steps of $1 \mathrm{~min}$ during continuous aerosol sampling. Values referring to longer time intervals are calculated as averages from the basic $1 \mathrm{~min}$ data.

In addition to the MAAP method that utilizes the instrument's internal algorithm, the absorption coefficient can also be determined from the photodetector raw signals in a postprocessing procedure. The typically used print formats of the MAAP do not give the raw signals as an output, and have to be logged, e.g., by using the scientific print format 12 . These raw signals include the photodetector response signal at $0^{\circ}$ (transmittance), and signals at 130 and $165^{\circ}$ (reflectance). From the 0 and $165^{\circ}$ signals, the light attenuation (ATN) by the sample can be determined as

$b_{\text {ATN }, \text { TRANS }}=\frac{A}{V} \ln \left(\frac{T_{0}}{T}\right)$

$b_{\mathrm{ATN}, \mathrm{REFL}}=0.5 \times \frac{A}{V} \ln \left(\frac{R_{0}}{R}\right)$

where $\left(T_{0} / T\right)$ and $\left(R_{0} / R\right)$ are the ratios of photodetector signals at 0 and $165^{\circ}$ for a particle loaded and a particlefree filter, respectively. The factor 0.5 in the reflectance measurement results from the fact that the light passes through the layer of sampled aerosol twice before reaching the photodetector.

The measured properties $b_{\mathrm{ATN}}$,TRANS and $b_{\mathrm{ATN}, \mathrm{REFL}}$ cannot be used directly to obtain the $\mathrm{BC}$ mass concentration, because typical filter loading artifacts affect the measured signals. Petzold et al. (2005) determined relationships for the $b_{\mathrm{AP}}$ and $b_{\mathrm{ATN} \text {,TRANS }}$ as well as $b_{A T N, R E F L}$ by utilizing test aerosols. These test aerosols consisted of pure black aerosol samples from kerosene flame particles, and externally mixed gray and black aerosols of varying single scattering albedo. The correction functions are

$$
\begin{aligned}
b_{\mathrm{AP}, \mathrm{TRANS}} & =b_{\text {ATN,TRANS }} \times\left(0.654+3.314 T / T_{0}\right)^{-1} \\
& \times\left(1.0+0.0015 \exp \left(\omega_{0} / 0.17\right)\right)^{-1} \\
b_{\mathrm{AP}, \mathrm{REFL}}= & b_{\mathrm{ATN}, \mathrm{REFL}} \times\left(0.226+1.415 R / R_{0}\right)^{-1}
\end{aligned}
$$

where $\omega_{0}$ is the single scattering albedo of the aerosol.

Finally, the absorption coefficients obtained with different methods (MAAP, TRANS and REFL) are directly proportional to the $\mathrm{BC}$ mass concentration $\left(\mathrm{BC}_{\mathrm{METHOD}}\right)$ by a factor of $1 / \sigma_{\mathrm{BC}}$, where $\sigma_{\mathrm{BC}}=6.6 \mathrm{~m}^{2} \mathrm{~g}^{-1}$, the mass-specific absorption cross section of $\mathrm{BC}$ at a wavelength of $637 \mathrm{~nm}$.

The increase of $\mathrm{BC}$ mass deposited on the filter spot during one time interval of sampling, or $\mathrm{BC}$ mass accumulation rate $\Delta \mathrm{BC}$ in $\mu \mathrm{g} \mathrm{cm}^{-2}$, is calculated accordingly as

$$
\begin{aligned}
& \Delta \mathrm{BC}\left(t_{i}\right)=\left[\left(1-\omega_{\mathrm{FILTER}}\left(t_{i}\right)\right) \times \tau_{\text {FILTER }}\left(t_{i}\right)\right. \\
& \left.-\left(1-\omega_{\mathrm{FILTER}}\left(t_{i-1}\right)\right) \times \tau_{\text {FILTER }}\left(t_{i-1}\right)\right] \times \frac{1}{\sigma_{\mathrm{BC}}} .
\end{aligned}
$$

The value of $\sigma_{\mathrm{BC}}$ was determined from a series of lab and ambient measurements (Petzold and Schönlinner, 2004) against gravimetric and thermal reference methods. It is in close agreement with the value of $7.5 \pm 1.2 \mathrm{~m}^{2} \mathrm{~g}^{-1}$ at $550 \mathrm{~nm}$ for "fresh" carbonaceous aerosol (Bond and Bergstrom, 2006) taking into account scaling of $\sigma_{\mathrm{BC}}$ with the inverse wavelength.

\section{MAAP artifact and correction}

\subsection{Initial observations}

The artifact was first noticed during measurements at the EUCAARI station in Gual Pahari (India). The station was located about $25 \mathrm{~km}$ south of New Delhi. Typical for the IndoGangetic plains, the region is heavily polluted. For the measurement campaign period of December 2007-January 2010, the $\mathrm{PM}_{10}$ and $\mathrm{PM}_{2.5}$ average values were $216 \mu \mathrm{g} \mathrm{m}^{-3}$ and $126 \mu \mathrm{g} \mathrm{m}^{-3}$, respectively (Hyvärinen et al., 2010). The average $\mathrm{BC}$ mass concentration was found to be $12.3 \mu \mathrm{g} \mathrm{m}^{-3}$. The $\mathrm{BC}$ measurements were conducted utilizing a $\mathrm{PM}_{10}$ inlet, and the aerosol was dried by a diffusion drier prior to entering the instrument. The MAAP (Thermo Scientific Model 5012) was run at a nominal flow rate of $8 \mathrm{~L} \mathrm{~min}^{-1}$. The data were mostly saved as 5 or $1 \mathrm{~min}$ averages.

During high concentration periods, an artificial decrease in concentration was observed in the MAAP data at Gual Pahari (Fig. 2). The artifact is related to the filter spot change conducted by the instrument; i.e., when a new blank filter spot is moved into the sampling head, the observed BC concentration decreases. The artifact is clearly not related to the typical filter loading effects, which result in concentration increase rather than decrease after the filter spot change (e.g., Virkkula et al., 2007; Petzold et al., 2005).

For a better understanding of the artifact, we analyzed the instrument raw signals from the MAAP at Gual Pahari. Using Eqs. (1)-(5) and the absorption cross section $\sigma_{\mathrm{BC}}$, the whole dataset was converted to three different $\mathrm{BC}$ values: $\mathrm{BC}_{\mathrm{MAAP}}, \mathrm{BC}_{\mathrm{TRANS}}$ and $\mathrm{BC}_{\mathrm{REFL}}$. The $\omega_{0}$ in Eq. (4) for calculating $b_{\mathrm{AP} \text {,TRANS }}$ was estimated to be 0.9 , which is typical for ambient aerosols. This choice was found to affect the magnitude but not the shape of the transmitted signal.

When comparing the results obtained with the three different methods (Fig. 2), it becomes apparent that the artifact is already present in the raw photodetector signals, especially 


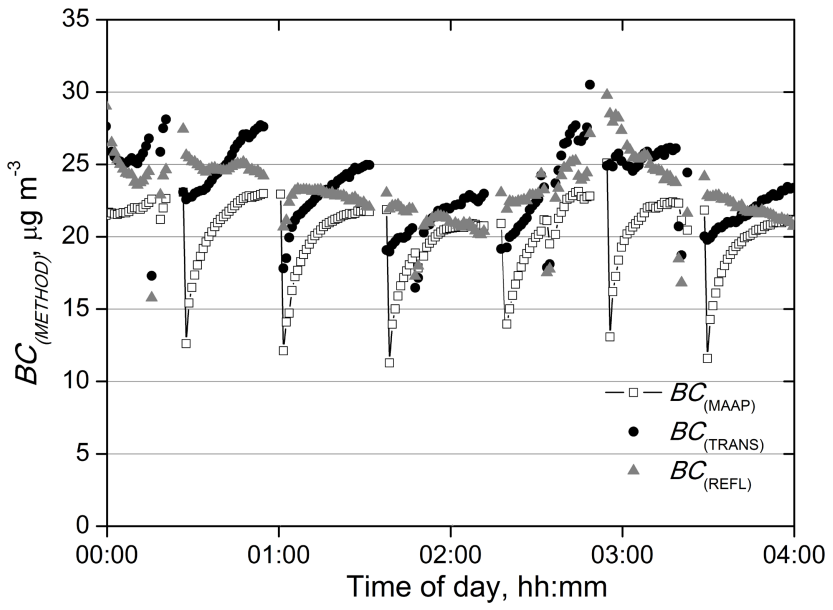

Fig. 2. Comparison of $\mathrm{BC}$ measured with the MAAP by multi-angle photometry $\mathrm{BC}_{\mathrm{MAAP}}$, transmission $\mathrm{BC}_{\mathrm{TRANS}}$ and reflectance $\mathrm{BC}_{\mathrm{REFL}}$ methods during a high concentration episode in Gual $\mathrm{Pa}$ hari, India, 12 August 2009.

in the transmitted $0^{\circ}$ signal. $\mathrm{BC}_{\text {TRANS }}$ almost mimics the behavior of $\mathrm{BC}_{\mathrm{MAAP}}$, although showing somewhat higher concentrations in general. $\mathrm{BC}_{\mathrm{REFL}}$ exhibits a much weaker, yet visible artifact effect. It is also notable in Fig. 2 that, during the few minutes when the filter spot change takes place, there is a strong scattering in the raw signal, which is related to stabilization of the instrument. The exact mechanism causing the artifact is not known, but it seems to be related to erroneous dark counts in the photodetector measuring the transmitted light during the filter zeroing procedure, in combination with an instrument internal averaging procedure of the photodetector raw signals.

\subsection{Quantification of the artifact}

A laboratory test was conducted to accurately quantify the artifact. The basic assumption for designing the quantification experiment was that the observed artifact is closely related to the $\mathrm{BC}$ mass accumulation rate $\triangle \mathrm{BC}$ in $\mu \mathrm{g} \mathrm{min}{ }^{-1}$. Hence, two MAAP instruments were set up to sample from the same aerosol but operated on different volume flow rates. This in turn resulted in different values for $\triangle \mathrm{BC}$.

Test aerosol was produced by atomizing a water solution of "Aquadaq", a soot reference standard (Baumgardner et al., 2012), into a mixing volume of $\sim 5 \mathrm{~L}$. Two MAAP instruments sampled from this mixing volume - one $(s / n 145)$ with a high flow rate (16-20 $\left.\mathrm{L} \mathrm{min}^{-1}\right)$, and the other $(s / n 87)$ with a low flow rate $\left(7-10 \mathrm{~L} \mathrm{~min}^{-1}\right)$. Make-up air was taken from the lab through a HEPA filter. The concentration of $\mathrm{BC}$ was changed by changing the flow rate of the atomizer. MAAP flow rates were calibrated against a Gilibrator bubble flow meter. The concentration- and flow rate-ratios were controlled so that the artifact occurred only in the high flow rate
MAAP, thus utilizing the low flow rate MAAP as a reference instrument.

As the photodetector response (and thus the mass accumulation rate) depends both on the $\mathrm{BC}$ mass concentration and the flow rate $Q$ of the instrument, we express the laboratory results in terms of $\triangle \mathrm{BC}=\mathrm{BC} \times Q$, i.e., accumulation rates. We prefer to use this notation, as both $\mathrm{BC}$ and $Q$ can be logged with the MAAP standard print formats. Cumulatively, this also becomes the mass on the filter spot, $m$. The results indicate that at $\mathrm{BC}$ mass accumulation rates $>\sim 0.04 \mu \mathrm{g} \mathrm{min}^{-1}$ the artifact can be identified from the data. The observed artifact is very systematic. After an initial drop, the $\mathrm{BC}$ signal increases with a rate proportional to the prevailing $\mathrm{BC}$ concentration. The artifact can be roughly divided in three distinct regions (Fig. 3a):

1. At moderately high mass accumulation rates $(0.04 \mu \mathrm{g}$ $\min ^{-1}<\mathrm{BC} \times Q<0.08 \mu \mathrm{g} \mathrm{min}{ }^{-1}$ ), only the very first minutes experience a decrease of the signal, followed by a prominent increase above the initial signal level, before stabilization back to the correct level occurs.

2. At high mass accumulation rates $\left(0.08 \mu \mathrm{g} \mathrm{min}{ }^{-1}\right.$

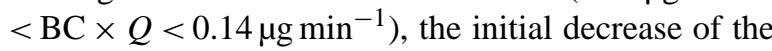
signal becomes more apparent compared to the following overestimation. However, the point where the concentration stabilizes back to the correct level is still very distinct, as it is characterized by 1 or 2 min of clearly higher concentrations.

3. At very high mass accumulation rates $(\mathrm{BC} \times Q>$ $\left.0.14 \mu \mathrm{g} \mathrm{min}{ }^{-1}\right)$, the initial signal decrease is so strong that the signal never recovers to the correct level before the next filter spot change, leading to an inevitable underestimation of the $\mathrm{BC}$ concentration. This reveals that an erroneous temporal response is not the only outcome of the artifact. At high enough BC concentrations, the MAAP underestimates BC values entirely (Fig. 3b).

\subsection{Correction algorithm}

To compile a correction algorithm, we addressed the two principal problems present in the original data, i.e., (1) the overall concentrations, which are underestimated when the rising MAAP signal cannot reach the true concentration (Fig. 3b), and (2) the temporal response of the erroneous concentrations (Fig. 3a).

1. The overall correction was made by correlating the smoothed data from the high flow rate MAAP with the data from the reference low flow rate MAAP. The smoothed concentrations, $\mathrm{BC}_{\text {smooth }}$, could simply be the last few minutes before the next filter spot change, by removing the other data suffering from the artifact. The correlation can be described with a third level polynomial resulting in the corrected $\mathrm{BC}_{\mathrm{CORR}} \times Q$ : 
a.)

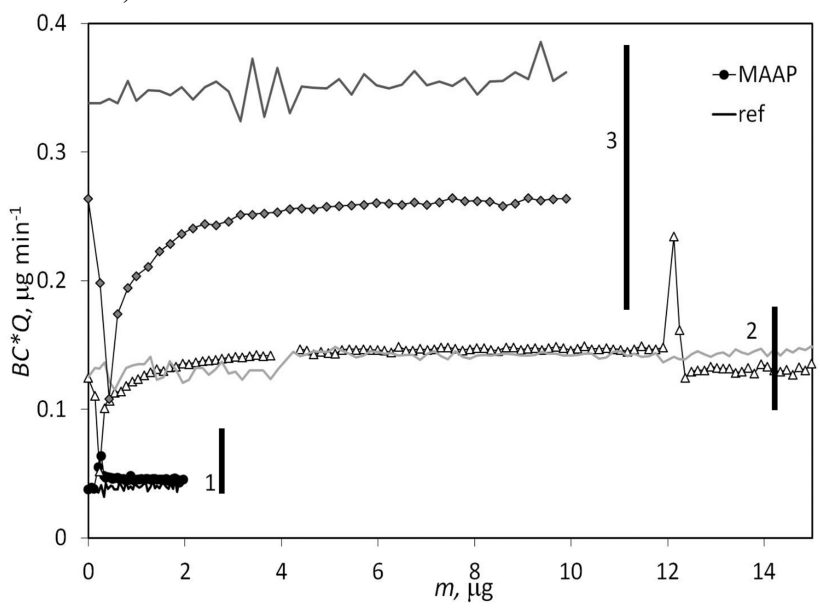

b.)

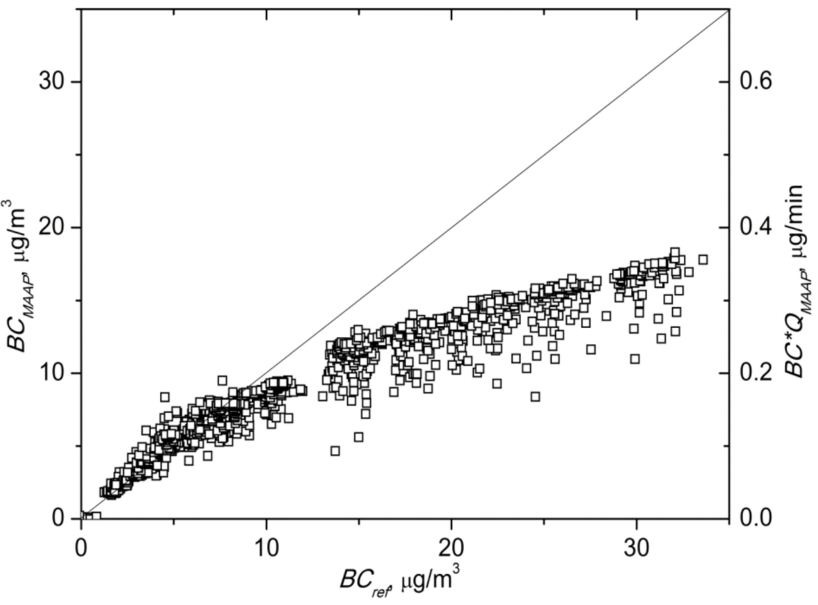

Fig. 3. (a) Examples of the artifact temporal response. Symbol lines indicate data from the high flow rate MAAP, and solid lines data from the reference MAAP. Regimes 1, 2 and 3 correspond to accumulation rates $(\mathrm{BC} \times Q)$ of $0.04-0.08 \mu \mathrm{g} \mathrm{min}{ }^{-1}, 0.08-0.14 \mu \mathrm{g} \mathrm{min}{ }^{-1}$ and $>0.14 \mu \mathrm{g} \mathrm{min}^{-1}$, respectively. See text for details. (b) Comparison of the low flow rate reference $\left(\mathrm{BC}_{\mathrm{ref}}\right)$ and high flow rate $\left(\mathrm{BC} \mathrm{MAAP}_{\mathrm{A}}\right) \mathrm{BC}$ concentrations.

$$
\begin{aligned}
\mathrm{BC}_{\mathrm{CORR}} \times Q & =5.665 \pm 0.25\left(\mathrm{BC}_{\text {smooth }} \times Q\right)^{3} \\
& +0.203 \pm 0.113\left(\mathrm{BC}_{\text {smooth }} \times Q\right)^{2} \\
& +0.9363 \pm 0.0116\left(\mathrm{BC}_{\text {smooth }} \times Q\right) .(7)
\end{aligned}
$$

In conditions with changing concentrations, only considering data from a few minutes before each spot change might be misleading due to the poor time resolution.

2. In order to smooth the temporal response, we assumed that the real concentration is a sum of the extracted artifact signal and real changes in the concentrations, and may thus be expressed as

$$
\mathrm{BC}_{\text {smooth }}=\mathrm{BC}_{\text {ini }}+\left(\mathrm{BC}_{\text {meas }}-\mathrm{BC}_{\text {artifact }}\right)
$$

where $\mathrm{BC}_{\mathrm{ini}}$ is the concentration before the spot change, $\mathrm{BC}_{\text {meas }}$ the measured non-corrected concentration and $\mathrm{BC}_{\text {artifact }}$ the artifact signal dependent on the initial concentration described below.

The shape of the MAAP artifact signal can be described with the so-called Hill function as a function of the mass of BC on the filter spot, $m$ :

$\mathrm{BC}_{\text {artifact }} \times Q=\mathrm{BC}_{\max } \times Q \frac{m^{n}}{m^{n}+k^{n}}$

where $\mathrm{BC}_{\max } \times Q$ is the maximum plateau value simulated by the Hill function, and $k$ and $n$ are parameters describing the slope of the rising mass accumulation rate.
The measured accumulated mass was chosen as the base for characterizing the artifact, as it is a reasonable assumption that the artifact is dependent on both the initial mass accumulation rate and the change of accumulated mass on the filter spot. The laboratory cases were fitted with this function, and the parameters $\mathrm{BC}_{\max } \times Q$, $k$ and $n$ were optimized (Supplement). The parameters can be expressed with the following functions and constants:

$\mathrm{BC}_{\max } \times Q=0.8792 \times\left(\mathrm{BC}_{\text {ini }} \times Q\right)+0.0347$

$k=1.6623 \times\left(\mathrm{BC}_{\mathrm{ini}} \times Q\right)+0.0462$

$n=20.02 \times\left(\mathrm{BC}_{\mathrm{ini}} \times Q\right)^{2}-4.6454 \times\left(\mathrm{BC}_{\mathrm{ini}} \times Q\right)+1.428$

where $\mathrm{BC}_{\mathrm{ini}} \times Q$ is the mass accumulation rate in

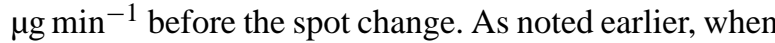
$\mathrm{BC} \times Q<0.14 \mu \mathrm{g} \mathrm{min}{ }^{-1}$, the artifact signal eventually makes an abrupt decrease back to the correct level (see Fig. 3a). This point was found to follow the relation:

$m_{\mathrm{d}}=0.1632 \times \exp \left(21.798 \times\left(\mathrm{BC}_{\mathrm{ini}} \times Q\right)\right)-0.4$.

The algorithm is not able to predict this decrease back to the real signal level, and should not be applied if the accumulated mass from the spot change is greater than $m_{\mathrm{d}}$ (in $\mu \mathrm{g}$ ).

An overall representation of the laboratory results is illustrated in Fig. 4. The smoothed data $\left(\mathrm{BC}_{\text {smooth }}\right)$ correct for the temporal response, but not the overall underestimation. However, the polynomial regression (Eq. 7) brings the two datasets to a $1: 1$ ratio $\left(R^{2}=0.99\right)$. Equation (7) is valid for the mass accumulation rate $\left(\mathrm{BC}_{\mathrm{smooth}} \times Q\right)$ range of 0 $0.39 \mu \mathrm{g} \mathrm{min}^{-1}$. The equation is nearly linear in the range of 


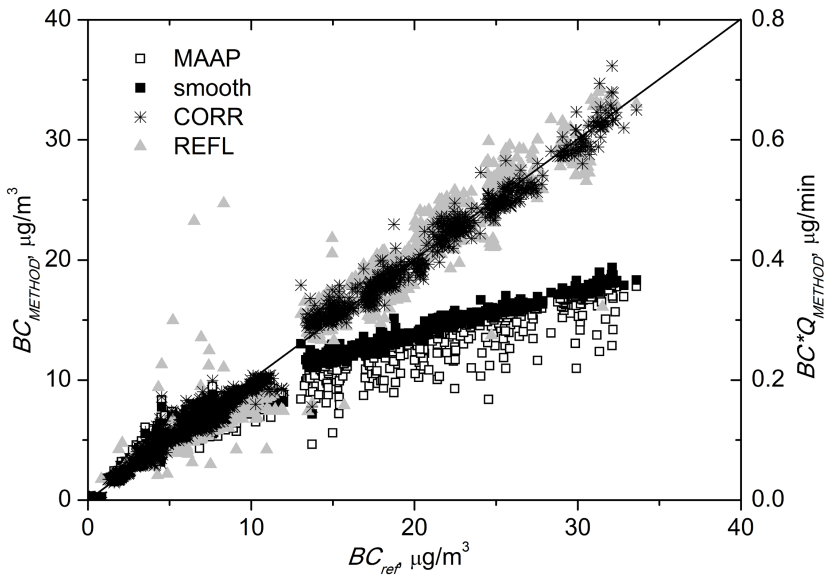

Fig. 4. High flow rate MAAP BC concentrations as a function of the reference (low flow rate) MAAP concentrations. $\mathrm{BC}_{\mathrm{MAAP}}$ is the original signal; $\mathrm{BC}_{\mathrm{smooth}}$ is the smoothed signal without an overall concentration correction. $\mathrm{BC}_{\mathrm{CORR}}$ is the smoothed signal with the overall concentration correction. $\mathrm{BC}_{\mathrm{REFL}}$ is the original signal determined with the reflectance method. The $1: 1$ ratio line is also shown.

$0-0.14 \mu \mathrm{g} \min ^{-1}$ with an average relative difference of $3.8 \%$ from a linear $1: 1$ correlation. The upper limit here is restricted by the artifact arising in the reference MAAP. The low flow rate data were used up to $\mathrm{BC} \times Q=0.14 \mu \mathrm{g} \mathrm{min}-1$ so that only the artifact-free data were chosen for the correlation. The average absolute deviation of the corrected measurement points of the high flow rate MAAP compared to the low flow rate MAAP was $0.49 \mu \mathrm{g} \mathrm{m}^{-3}$, and the corresponding average relative deviation was $5.4 \%$. The highest individual deviations typically occur during the first $2-3 \mathrm{~min}$ after the filter spot change, due to the very steep signal increase of the artifact.

\subsection{Correction from the raw reflectance signal}

Similarly to field observations in Gual Pahari, the laboratory dataset was also converted to $\mathrm{BC}_{\mathrm{REFL}}$ using Eqs. (3) and (5). We see that these data follow the reference concentrations closely (Fig. 4$)$, although with more scatter $\left(R^{2}=0.96\right)$. Obviously the reflectance signal is not affected by the measurement artifact. This observation may indicate that the measurement artifact is occurring only in the processed transmission signal, which then affects also the final MAAP output signal while the reflectance signal only, with appropriately applied corrections of the filter matrix effect (Petzold et al., 2005), is not affected by the artifact and reports accurate BC mass concentration values. This presents an opportunity to utilize the reflected signal from the MAAP when mass accumulation rates are high enough that the artifact appears. However, as most of the print formats of the MAAP do not give the raw signals as an output, the algorithm is a useful way for correcting the results.

\section{Application of correction to ambient measurements}

Three ambient datasets were chosen for testing the correction algorithm: Gual Pahari (India) (Hyvärinen et al., 2010); Beijing (Garland et al., 2009) (China), and Welgegund (South Africa) (Beukes et al., 2012; www.welgegund.org). All these locations suffer from such high $\mathrm{BC}$ concentrations that the measurement artifact could be observed from the data.

In Gual Pahari, the MAAP was run at $8 \mathrm{~L} \mathrm{~min}^{-1}$. The correction algorithm was applied to the full dataset from 14 December 2007 to 19 January 2010. In Beijing, the flow rate of the MAAP was measured to be $9.2 \mathrm{~L} \mathrm{~min}^{-1}$. The algorithm was applied to a short-term dataset from 10 August 2006 to 9 September 2006, for which we could additionally utilize a PAS as reference method for the absorption of BC. Finally, in Welgegund (South Africa) a MAAP was run at a flow rate of $16.7 \mathrm{~L} \mathrm{~min}^{-1}$. These data covered the period from 1 June 2010 to 31 August 2010.

Using the algorithm (Eqs. 7-10) clearly improves the temporal response of the MAAP signal, removing most of the signal decreases observed in the uncorrected data from all three locations (Fig. 5a, c and e). On occasion, the first points after a filter spot change still show a concentration decrease for $\mathrm{BC}_{\mathrm{CORR}}$, which is due to the steep shape of the artifact: a small uncertainty in $m$ (accumulated mass) can lead to a large uncertainty in BC. In addition, problematic situations may occur when the true concentration exhibits a high gradient during the filter spot change. This can happen especially if there are short-term pollution episodes taking place. In such cases the assumption that the last value of $\mathrm{BC}$ on the previous filter spot equals the initial concentration is not valid. This has direct consequences on both the modeled new concentration and the length of the artifact effect. If there is a $\mathrm{BC}$ concentration decrease during the filter spot change, the concentrations would be underestimated and the last point of the artifact, $m_{\mathrm{d}}$, would be overestimated. For an increase, the effect is the opposite. As seen in the example figures, $\mathrm{BC}_{\mathrm{REFL}}$ may occasionally show values lower (Fig. 5a) or higher (Fig. 5e) than $\mathrm{BC}_{\mathrm{CORR}}$. However, the overall trends produced by the two methods are very similar.

In order to better evaluate the performance of the suggested correction algorithm, we compared the original $\mathrm{BC}_{\mathrm{MAAP}}$ and the corrected $\mathrm{BC}_{\mathrm{CORR}}$ against $\mathrm{BC}_{\mathrm{REFL}}$ from all three ambient locations (Fig. 5b, d and f). The erroneous temporal response of $\mathrm{BC}_{\mathrm{MAAP}}$ is again evident from the downward "tails" appearing in the figures. In addition, $\mathrm{BC}_{\text {MAAP }}$ underestimates the higher concentrations, similarly to what was seen in the laboratory experiments. Linear regressions fitted to the data (Table 1) do not indicate a substantial difference between the relations $\mathrm{BC}_{\mathrm{MAAP}}$ vs. $\mathrm{BC}_{\mathrm{REFL}}$ and $\mathrm{BC}_{\mathrm{CORR}}$ vs. $\mathrm{BC}_{\mathrm{REFL}}$. However, this is mostly because the median concentration is well below $10 \mu \mathrm{g} \mathrm{m}^{-3}$ at all the locations. The regressions do reveal that the correlation at all locations is improved by the correction. For Welgegund, the correlation is worst $\left(R^{2}=0.94\right)$, 

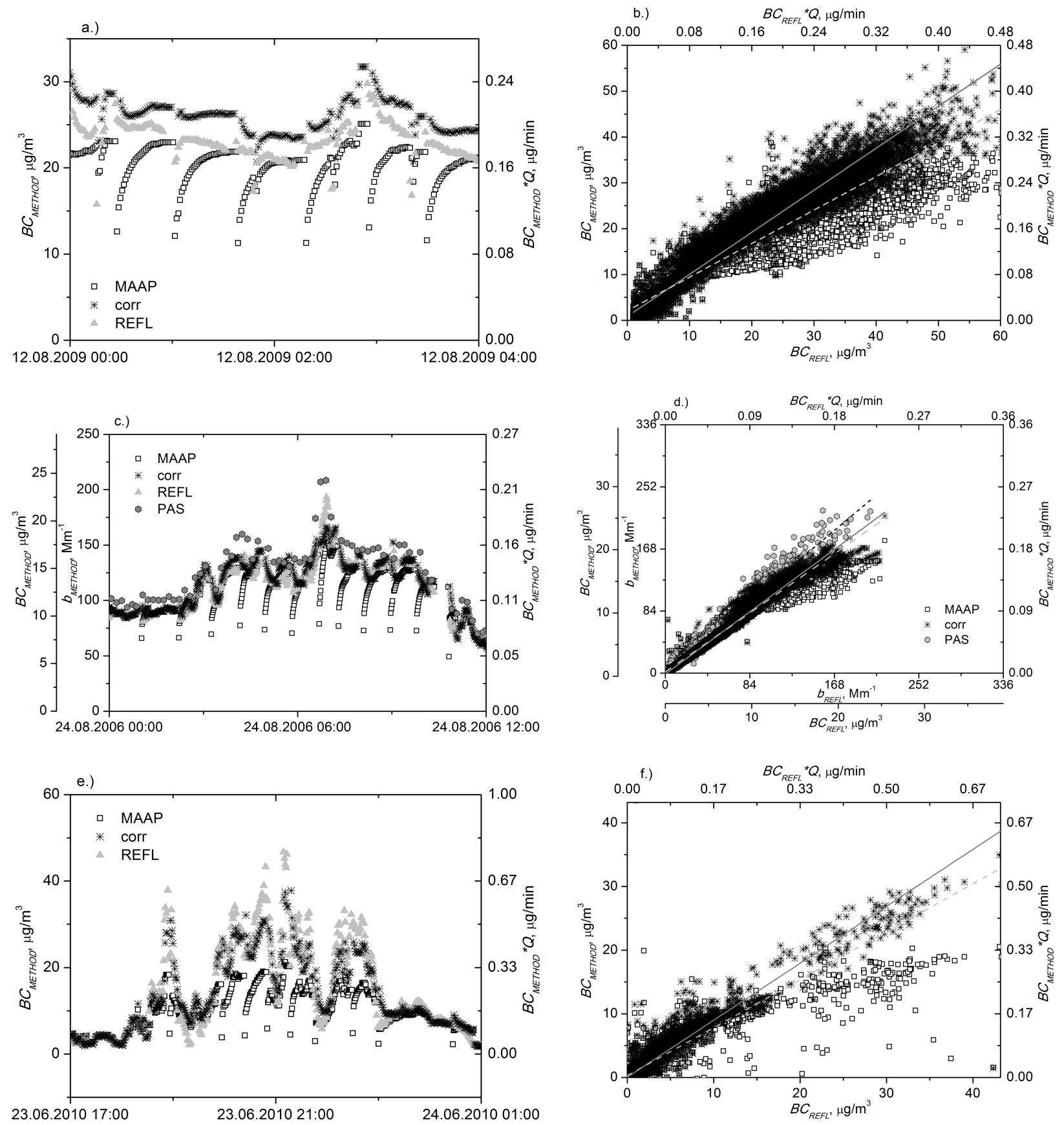

Fig. 5. Examples of the correction algorithm applied to the datasets from Gual Pahari (a, b), Beijing (c, d), and Welgegund (e, f). In panels (b), (d), and (f) the datasets from different methods are compared against the reflected BC signal, $\mathrm{BC}_{\mathrm{REFL}}$. Lines in these figures are linear fits to data. BC in Beijing was measured with $1: 1$ dilution. For Beijing, the absorption coefficients $b_{\text {METHOD }}$ at $532 \mathrm{~nm}$ from the PAS and those derived from the MAAP (see text for details) are also shown.

and in general $\mathrm{BC}_{\mathrm{REFL}}$ is higher than $\mathrm{BC}_{\mathrm{CORR}}$. At this location, high $\mathrm{BC}$ concentrations are related to pollution episodes, and $90 \%$ of data points are below $\sim 3 \mu \mathrm{g} \mathrm{m}^{-3}$. It is possible that the poorer correlation in Welgegund is related to the assumptions made in the determination of
$\mathrm{BC}_{\mathrm{REFL}}$. Also in Gual Pahari, $\mathrm{BC}_{\mathrm{REFL}}$ is generally higher than $\mathrm{BC}_{\mathrm{CORR}}$. Opposite to Welgegund, here the difference is probably related to the very high overall concentrations (90th percentile $=24.5 \mu \mathrm{g} \mathrm{m}^{-3}$, maximum $73.1 \mu \mathrm{g} \mathrm{m}^{-3}$ ). At mass accumulation rates higher than the applicability of the 
Table 1. Linear regression analysis of $\mathrm{BC}_{\mathrm{MAAP}}, \mathrm{BC}_{\mathrm{CORR}}$ and $\mathrm{BC}_{\mathrm{PAS}}$ against $\mathrm{BC}_{\mathrm{REFL}}$ at three ambient locations. 10th percentile, median and 90th percentile of the concentrations (in $\mu \mathrm{g} \mathrm{m}^{-3}$ ) are also shown.

\begin{tabular}{lcccccccc}
\hline $\begin{array}{c}\text { Measurement } \\
\text { site }\end{array}$ & $\begin{array}{c}\text { Data } \\
\text { points }\end{array}$ & $\begin{array}{c}\text { 10th } \\
\text { perc. }\end{array}$ & Median & $\begin{array}{c}\text { 90th } \\
\text { perc. }\end{array}$ & Method & $A$ & $B$ & $R^{2}$ \\
\hline Gual Pahari & 240000 & 2.3 & 7.6 & 24.5 & MAAP & 0.73 & 2.10 & 0.91 \\
& & & & & CORR & 0.92 & 0.84 & 0.96 \\
Beijing & $\sim 41000$ & \multirow{2}{*}{1.1} & \multirow{2}{*}{4.2} & \multirow{2}{*}{10.1} & MAAP & 0.94 & 2.08 & 0.98 \\
& & & & & CORR & 1.00 & -1.20 & 0.99 \\
& & & & & PAS & 1.14 & 1.08 & 0.97 \\
Welgegund & $\sim 130000$ & 0.3 & \multirow{2}{*}{1.1} & 2.8 & MAAP & 0.75 & 0.29 & 0.86 \\
& & & & & CORR & 0.90 & 0.05 & 0.94 \\
\hline
\end{tabular}

$\mathrm{BC}_{\mathrm{METHOD}}=A^{*} \mathrm{BC}_{\mathrm{REFL}}+B$

correction function $(0.4 \mu \mathrm{g} \mathrm{min}-1)$, concentrations may be underestimated. While we cannot say with certainty which method produces the most accurate results, it has to be kept in mind that $\mathrm{BC}_{\mathrm{REFL}}$ is corrected from the raw photomultiplier signal by an empirical function based on test aerosols (Eq. 5). In ambient conditions, especially of high loading with strongly scattering aerosol, Eq. (5) may not be valid. The results do, however, indicate that the artifact correction based on the laboratory experiment may be applied to different ambient environments.

Finally, we were able to compare the results from a PAS against those derived from the MAAP in Beijing. The absorption coefficient values from MAAP at $637 \mathrm{~nm}$ were converted to those at $532 \mathrm{~nm}$ (PAS wavelength) by assuming an absorption Ångström exponent of 1. In addition, the MAAP in Beijing was run with $1: 1$ dilution, while the PAS sampled without dilution, so the MAAP absorption coefficients were further multiplied by 2 . Although the results from the MAAP are slightly lower (by $15 \%$ ) than those reported from the PAS (Fig. 5d and Table 1), the difference can be considered acceptable for a correction scheme. Similar and consistent results compared to a PAS were obtained, when the algorithm was applied to MAAP data from another megacity region, Guangzhou, China (Garland et al., 2008; R. M. Garland, private communication, 2012). This agreement further confirms our laboratory findings.

\section{Conclusions}

We have observed a measurement artifact in the MAAP at high $\mathrm{BC}$ concentrations. The artifact is related to the filter spot change - as mass is accumulated on a fresh filter spot, the photodetector response of the transmitted $0^{\circ}$ light is lower than anticipated. However, the $165^{\circ}$ photodetector signal is not compromised. The artifact seems to be related to erroneous dark counts in the transmitted light photodetector, in combination with an instrument internal averaging procedure of the photodetector raw signals. The artifact behavior however appears to be entirely related to the currently implemented data inversion algorithm, but not to any unknown physical processes. Using raw data on a $1 \mathrm{~Hz}$ basis and post-processing the data independently by an algorithm similar to that described by Petzold and Schönlinner (2004) shows no artifacts as described here (T. Onasch, private communication, 2011). The artifact can be observed if the BC mass accumulation rate $\mathrm{BC} \times Q$ exceeds $0.04 \mu \mathrm{g} \mathrm{min}{ }^{-1}$. At the typical flow rate of $1 \mathrm{~m}^{3} \mathrm{~h}^{-1}$, this relates to a $\mathrm{BC}$ concentration of $\sim 3 \mu \mathrm{g} \mathrm{m}^{-3}$. Overall concentrations of uncorrected MAAP data are underestimated if $\mathrm{BC} \times Q$ exceeds $0.14 \mu \mathrm{g} \mathrm{min}^{-1}$. With increasing $\mathrm{BC}$ accumulation rate, the underestimation may be several tens of percent.

We compiled an algorithm to correct the BC estimation from the typically most commonly used print formats of the MAAP. The algorithm is not dependent on the saving interval of the data and takes the instrument flow rate into account. The algorithm was tested on data originating from three different ambient environments, and was found to improve all the datasets considerably. In principle, the artifact can also be avoided by diluting the sampled air, but this will result in a loss of accuracy at lower concentrations. The MAAPreflected signal may also be used to derive correct concentration levels. Therefore, it is strongly recommended to log the raw reflectance signals of MAAPs in highly polluted environments. However, utilizing solely the reflected signal may result in an increased noise in the data.

An updated version of the MAAP firmware is currently in preparation for distribution. However, the correction algorithm as described here is urgently needed for correcting data from worldwide operated MAAP instruments.

\section{Supplementary material related to this article is available online at: http://www.atmos-meas-tech.net/6/ 81/2013/amt-6-81-2013-supplement.pdf.}


Acknowledgements. EUCAARI and The Finnish Foreign Ministry's "Particulate pollution and the Indian Brown cloud associated with it" are acknowledged for funding the measurements in India.

Academy of Finland: 132640 , Atmospheric monitoring capacity building in Southern Africa, [2010-2012]

Academy of Finland: 117505 , Air pollution in Southern Africa (APSA) [2006-2009]

Nesslingin säätiö: Ilmansaasteiden ja lumisateen vuorovaikutus arktisilla alueilla

\section{EU LIFE+ project LIFE09 ENV/FI/000572 MACEB}

The contributions of R. M. Garland, M. O. Andreae, and U. Pöschl were supported by the Max Planck Society, Germany.

We thank Aki Virkkula for the helpful discussions. We also thank Timothy B. Onasch from Aerodyne Research Inc. for in-depth discussions on the observed measurement artifact and potential explanations.

Edited by: W. Maenhaut

\section{References}

Andreae, M. O. and Gelencsér, A.: Black carbon or brown carbon? The nature of light-absorbing carbonaceous aerosols, Atmos. Chem. Phys., 6, 3131-3148, doi:10.5194/acp-6-3131-2006, 2006.

Arnott, W. P., Hamasha, K., Moosmüller, H., Sheridan, P. J., and Ogren, J. A.: Towards Aerosol Light-Absorption Measurements with a 7-Wavelength Aethalometer: Evaluation with a Photoacoustic Instrument and 3-Wavelength Nephelometer, Aerosol. Sci. Tech., 39, 17-29, 2005.

Baumgardner, D., Popovicheva, O., Allan, J., Bernardoni, V., Cao, J., Cavalli, F., Cozic, J., Diapouli, E., Eleftheriadis, K., Genberg, P. J., Gonzalez, C., Gysel, M., John, A., Kirchstetter, T. W., Kuhlbusch, T. A. J., Laborde, M., Lack, D., Müller, T., Niessner, R., Petzold, A., Piazzalunga, A., Putaud, J. P., Schwarz, J., Sheridan, P., Subramanian, R., Swietlicki, E., Valli, G., Vecchi, R., and Viana, M.: Soot reference materials for instrument calibration and intercomparisons: a workshop summary with recommendations, Atmos. Meas. Tech., 5, 1869-1887, doi:10.5194/amt-51869-2012, 2012.

Beukes, J. P., Vakkari, V., van Zyl, P. G., Venter, A. D., Josipovic, M., Jaars, K., Tiitta, P., Kulmala, M., Worsnop, D., Pienaar, J. J., Järvinen, E., Chellapermal, R., Ignatius, K., Maalick, Z., Cesnulyte, V., Ripamonti, G., Laban, T. L., Skrabalova, L., du Toit, M., Virkkula, A., and Laakso, L.: Source region plume characterisation of the interior of South Africa, as measured at Welgegund, in preparation, 2012.

Bond, T. C. and Bergstrom, R. W.: Light Absorption by Carbonaceous Particles: An Investigative Review, Aerosol Sci. Tech., 40, 27-67, 2006.

Bond, T. C., Anderson, T. L., and Campbell, D.: Calibration and intercomparison of filter-based measurements of visible light absorption by aerosols, Aerosol Sci. Tech., 30, 582-600, 1999.
Collaud Coen, M., Weingartner, E., Apituley, A., Ceburnis, D., Fierz-Schmidhauser, R., Flentje, H., Henzing, J. S., Jennings, S. G., Moerman, M., Petzold, A., Schmid, O., and Baltensperger, U.: Minimizing light absorption measurement artifacts of the Aethalometer: evaluation of five correction algorithms, Atmos. Meas. Tech., 3, 457-474, doi:10.5194/amt-3-457-2010, 2010.

Garland, R. M., Yang, H., Schmid, O., Rose, D., Nowak, A., Achtert, P., Wiedensohler, A., Takegawa, N., Kita, K., Miyazaki, Y., Kondo, Y., Hu, M., Shao, M., Zeng, L. M., Zhang, Y. H., Andreae, M. O., and Pöschl, U.: Aerosol optical properties in a rural environment near the mega-city Guangzhou, China: implications for regional air pollution, radiative forcing and remote sensing, Atmos. Chem. Phys., 8, 5161-5186, doi:10.5194/acp-85161-2008, 2008.

Garland, R. M., Schmid, O., Nowak, A., Achtert, P., Wiedensohler, A., Gunthe, S. S., Takegawa, N., Kita, K., Kondo, Y., Hu, M., Shao, M., Zeng, L. M., Zhu, T., Andreae, M. O., and Pöschl, U.: Aerosol optical properties observed during CAREBeijing2006: Characteristic differences between the inflow and outflow of Beijing city air, J. Geophys. Res.-Atmos., 114, D00G04, doi:10.1029/2008JD010780, 2009.

Hänel, G.: Radiation budget of the boundary layer: Part II. Simultaneous measurement of mean solar volume absorption and extinction coefficients of particles, Beitr. Phys. Atmos., 60, 241-247, 1987.

Hansen, A. D. A., Rosen, H., and Novakov, T.: The aethalometer an instrument for the real-time measurement of optical absorption by aerosol particles, Sci. Total Environ., 36, 191-196, 1984.

Hyvärinen, A.-P., Lihavainen, H., Komppula, M., Panwar, T. S., Sharma, V. P., Hooda, R. K., and Viisanen, Y.: Aerosol measurements at the Gual Pahari EUCAARI station: preliminary results from in-situ measurements, Atmos. Chem. Phys., 10, 72417252, doi:10.5194/acp-10-7241-2010, 2010.

Müller, T., Henzing, J. S., de Leeuw, G., Wiedensohler, A., Alastuey, A., Angelov, H., Bizjak, M., Collaud Coen, M., Engström, J. E., Gruening, C., Hillamo, R., Hoffer, A., Imre, K., Ivanow, P., Jennings, G., Sun, J. Y., Kalivitis, N., Karlsson, H., Komppula, M., Laj, P., Li, S.-M., Lunder, C., Marinoni, A., Martins dos Santos, S., Moerman, M., Nowak, A., Ogren, J. A., Petzold, A., Pichon, J. M., Rodriquez, S., Sharma, S., Sheridan, P. J., Teinilä, K., Tuch, T., Viana, M., Virkkula, A., Weingartner, E., Wilhelm, R., and Wang, Y. Q.: Characterization and intercomparison of aerosol absorption photometers: result of two intercomparison workshops, Atmos. Meas. Tech., 4, 245-268, doi:10.5194/amt-4-245-2011, 2011.

Petzold, A. and Schönlinner, M.: Multi-Angle Absorption Photometry - A New Method for the Measurement of Aerosol Light Absorption and Atmospheric Black Carbon, J. Aerosol Sci., 35, 421-441, 2004.

Petzold, A., Kramer, H., and Schönlinner, M.: Continuous Measurement of Atmospheric Black Carbon using a multi-Angle Absorption Photometer, Environ. Sci. Poll. Res., 4, 78-82, 2002.

Petzold, A., Schloesser, M., Sheridan, P. J., Arnott, W. P., Ogren, J. A., and Virkkula, A.: Evaluation of Multi-Angle Absorption Photometry for Measuring Aerosol Light Absorption, Aerosol Sci. Tech., 39, 40-51, 2005. 
Sheridan, P. J., Arnott, W. P., Ogren, J. A., Andrews, E., Atkinson, D. B., Covert, D. S., Moosmüller, H., Petzold, A., Schmid, B., Strawa, A. W., Varma, R., and Virkkula, A.: The Reno aerosol optics study: An evaluation of aerosol absorption measurement methods, Aerosol Sci. Tech., 39, 1-16, 2005.

Virkkula, A., Mäkelä, T., Hillamo, R., Yli-Tuomi, T., Hirsikko, A., Hämeri, K., and Koponen, I. K.: A simple procedure for correcting loading effects of aethalometer data, J. Air Waste Manage. Assoc., 57, 1214-1222, 2007.
Weingartner, E., Saathoff, H., Schnaiter, M., Streit, N., Bitnar, B., and Baltensperger, U.: Absorption of light by soot particles: determination of the absorption coefficient by means of aethalometers, J. Aerosol Sci., 34, 1445-1463, 2003. 